\title{
Ultrasound of echinococcal liver cysts
}

\author{
Petar Avramovski ${ }^{1 *}$, Maja Avramovska ${ }^{2}$, Liljana Simonovska - Hentu ${ }^{3}, K_{\text {osta Sotiroski }}{ }^{4}$ Pece Nikolovski ${ }^{5}$ and Emilija Sikole $^{6}$ \\ ${ }^{1}$ Clinical Hospital "D-r Trifun Panovski”, Department of internal medicine, Partizanska bb. 7000 Bitola, Macedonia, Professor of High Medical School and Faculty \\ of Veterinary Medicine, St. Clement of Ohrid University- Bitola, Partizanska bb. 7000 Bitola, Macedonia \\ ${ }^{2}$ University Clinic of Obstetrics and Gynecology, Specializing at University “SS. Cyril and Methodius”, Vodnjanska 17, 1000, Skopje, Macedonia \\ ${ }^{3}$ Clinical Hospital "D-r Trifun Panovski” Department of internal medicine and ultrasonography, Partizanska bb. 7000 Bitola, Macedonia \\ ${ }^{4}$ Faculty of Economis, Prilep, Professor of of Statistics, University "St. Kliment Ohridski" - Bitola, Macedonia \\ ${ }^{5}$ Faculty of Economis, Prilep, Professor at University "St. Kliment Ohridski” - Bitola, Macedonia \\ ${ }^{6}$ Institute of Preclinical and Clinical Pharmacology with Toxicology, University “SS. Cyril and Methodius”, Vodnjanska 17, 1000, Skopje, Macedonia
}

\section{Introduction}

Cystic echinococcosis (CE) is a widely endemic helminthic disease caused by infection with metacestodes (larval stage) of the Echinococcus granulosus tapeworm [1]. Larval infection, cystic echinococcosis, is characterised by long term development of hydatid cysts in the intermediate host [2]. Hydatid cyst is caused by Echinococcus infection, resulting in cyst formation anywhere in the body [liver (commonest), lung ( $2^{\text {nd }}$ commonest), spleen, central nervous system, retroperitoneal and musculoskeletal organs]. Humans are accidental host and the infection occurs by ingesting food contaminated with Echinococcus eggs. Different methods, based on morphology, physiology, biochemistry or molecular genetics, have been used for strain differentiation of Echinococcus (two main strains: echinococcus granulosus (common) and echinococcus alveolaris/multilocularis: less common but more invasive [3].

Upon infection with CE, cyst formation mainly occurs in the liver (70\%). Diagnosis involves serum serologic testing for antibodies against hydatid antigens (test for indirect hemagglutination, sensitivity of $90 \%$ in hepatic echinococcus and $40 \%$ for pulmonary echinococcus) [4], but preferably with imaging by ultrasound or computed tomography or electromagnetic resonance. The indirect hemagglutination test and the enzyme-linked immunosorbent assay (ELISA) and are the initial screening tests of choice. Treatment methods include chemotherapy with benzimidazole carbamates and/or surgical approaches, including percutaneous aspiration injection and respiration.

\section{Ultrasound in cystic echinococcosis}

Imaging techniques have revolutionized the diagnosis and clinical management of CE. Gharbi et al. [5] developed the first ultrasound classification for CE in 1981. Many other classifications were subsequently produced but were not widely adopted. The number of cyst types remains unchanged from Gharbi's classification and the types are categorized into active, transitional, and inactive stages. CE1 and 2 are active, usually fertile cysts containing viable protoscoleces. CE3 are cysts entering a transitional stage where the integrity of the cyst has been compromised either by the host or by chemotherapy. CE4 and CE5 are inactive cysts that have lost their fertility and are degenerating. A more recent amendment to the WHO classification clarifies that calcifications are not limited to CE5 cysts, but may be present to a various extent in all cystic stages and are therefore not indicative of cyst death [6].
B-mode hepatic sonogram shows well shaped large rounded hyperechoic solid appearing mass with inside appears of multiple hypoechoic curvilinear echoes clustered within mass without daughter cysts (Figure 1). It is suggestive for consolidating inactive hydatit cyst (the patient was under 3 months therapy with Albendazole, day dose $12 \mathrm{mg} / \mathrm{kg}$ ). Shams-Ul-Bari et al. (2011) conclude that albendazole is an effective adjuvant therapy in the treatment of hydatid liver disease [6,7] (Figure 1).

Figure 2 shows hydatid cysts of the liver detected by B-mode ultrasound. There is multiloculated appearance of the cyst due to the presence of multiple daughter cysts. This multiseptated anechoic (hypoechoic) appearance on B-mode sonography is typical of a hydatid cyst. Detached germinal membranes and brood capsules are seen in the more anterior daughter cyst (Figure 2).

Because of "echo enhancement" a hydatid cysts appears displaced beside their left liver lobe position. The ultrasound characteristics of the cyst determine its affiliation to CE3Bb according Gharbi's classification.

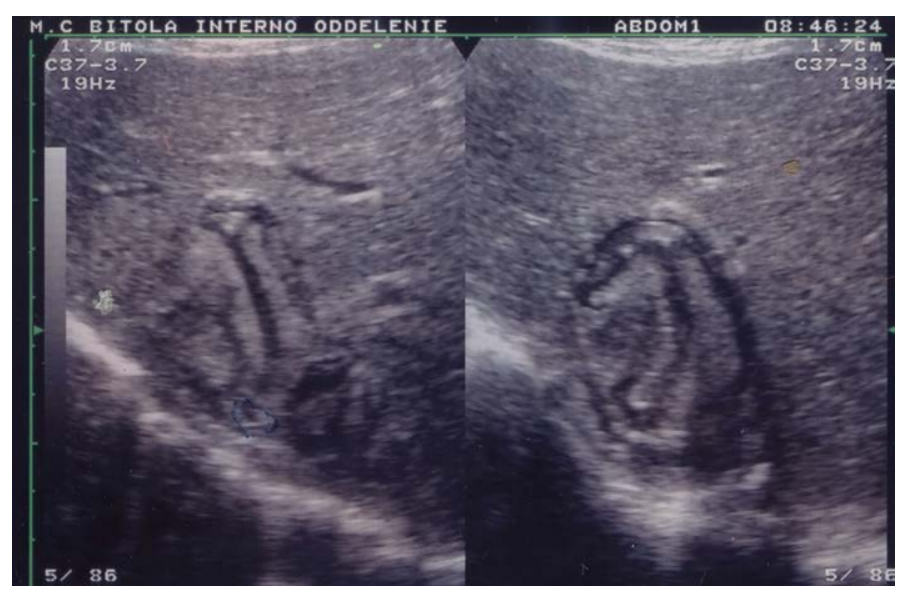

Figure 1. Large $(6.1 \times 4.0 \mathrm{~cm})$ rounded hyperechoic solid appearing mass with multiple hypoechoic curvilinear echoes clustered within mass (B-mode ultrasound of the liver).

Correspondence to: Professor d-r Petar Avramovski, Clinical Hospital "D-r Trifun Panovski", Department of internal medicine, Partizanska bb. 7000 Bitola, Macedonia, Professor of High Medical School and Faculty of Veterinary Medicine, St. Clement of Ohrid University- Bitola, Partizanska bb. 7000 Bitola, Macedonia, Tel: +389-70-207-187; E-mail: avramovski@gmail.com

Received: June 24, 2017; Accepted: July 19, 2017; Published: July 22, 2017 


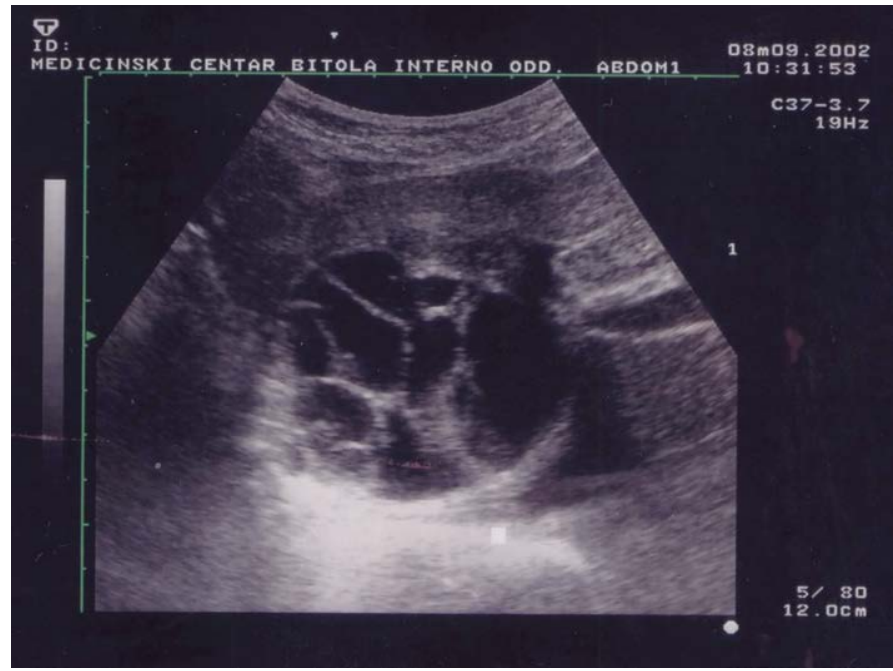

Figure 2. Multiple anechoic areas with hiperechogenic septa appearing as rounded mas in right lobe of the liver $(6.5 \times 4.85 \mathrm{~cm})$. Multiple large hydatid cysts (B-mode ultrasound of the liver).

The CE is showed in figure 3 and its confirmed findings from optical microscopy are equally likely being consistently viable.

\section{References}

1. Pakala T, Molina M, Wu GY (2016) Hepatic echinococcal cysts: A review. J Clin Transl Hepatol 4: 39-46.[Crossref]

2. Eckert J, Deplazes P (2004) Biological, epidemiological, and clinical aspects of echinococcosis, a zoonosis of increasing concern. Clin Microbiol Rev 17: 107-135. [Crossref]

3. Romig T, Dinkel A, Mackenstedt U (2006) The present situation of echinococcosis in Europe. Parasitol Int 55: 187-191. [Crossref]

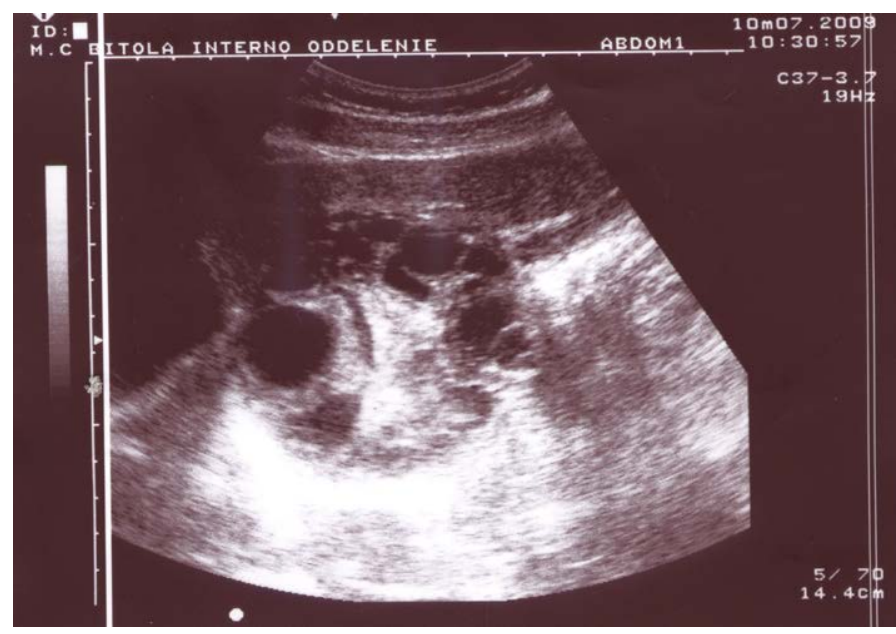

Figure 3. Multiple anechoic areas with central hyperechoic area appearing in left lobe of the liver $(7.3 \times 8.5 \mathrm{~cm})$ - hydatid cysts detected by B-mode ultrasound.

4. Savardashtaki A, Sarkari B, Arianfar F, Mostafavi-Pour Z (2017) Immunodiagnostic value of echinococcusgranulosus recombinant B8/1 subunit of antigen B. Iran $J$ Immunol 14: 111-122.[Crossref]

5. Gharbi HA, Hassine W, Brauner MW, Dupuch K (1981) Ultrasound examination of the hydatic liver. Radiology 139: 459-463.[Crossref]

6. Grisolia A, Troìa G, Mariani G, Brunetti E, Filice C (2009) A simple sonographic scoring system combined with routine serology is useful in differentiating parasitic from non-parasitic cysts of the liver. J Ultrasound 12: 75-79. [Crossref]

7. Shams-Ul-Bari, Arif SH, Malik AA, Khaja AR, Dass TA, et al. (2011) Role of albendazole in the management of hydatid cyst liver. Saudi J Gastroenterol 17: 343347.[Crossref]

Copyright: (C2017 Avramovski P. This is an open-access article distributed under the terms of the Creative Commons Attribution License, which permits unrestricted use, distribution, and reproduction in any medium, provided the original author and source are credited. 